\title{
Treatment of Industrial Effluents by MF and UF Ceramic Membranes: Comparative Study using Commercial and Elaborated Tunisian Clay Membranes
}

\author{
Sabeur Khemakhem* and Raja Ben Amar \\ Laboratoire des Sciences de Matériaux et Environnement, Faculté des Sciences de Sfax, Route de Soukra Km 4, 3038, Sfax, Tunisie
}

\begin{abstract}
Industrial effluents treatment was investigated using ceramic Microfiltration (MF) and Ultrafiltration (UF) tubular membranes. The comparison of performances between commercial ceramic membranes based on alumina material and elaborated ones based on Tunisian clay material was studied. MF and UF tests applied to cuttlefish effluent treatment were carried out respectively with $0.2 \mu \mathrm{m}$ and $5 \mathrm{~nm}$ commercial membranes and $0.18 \mu \mathrm{m}$ and $15 \mathrm{~nm}$ prepared membranes. The results show that for the two processes, the performances in term of permeate flux and quality of the treated wastewater using clay membranes was a little better than that obtained with commercial one.
\end{abstract}

Keywords: Commercial membrane; Tunisian clay membrane; Cuttlefish effluent; ultrafiltration; microfiltration

\section{Introduction}

Interest in separation by the use of membrane processes has gradually increased during the last $20-25$ years in many fields. The use of membranes increases the effectiveness of already existing processes and opens new possibilities for separation.

In the area of waste water treatment, membrane processes are often used in combination with other processes to treat very complex effluents which have often an important load of organic substances and salt. The membrane process would enhance the water treaded quality in order to water reuse [1]. Membrane can be in polymer or in inorganic material. Ceramic membranes have several advantages compared with polymeric membrane notably in term of mechanical strength and chemical and thermal resistances [2-4]. In addition, the amphoteric properties of ceramic surfaces permits in the area of desalination to assure selectivity of permeation and to produce water with a great performances compared to that resulted from reverse osmosis $[5,6]$. However, the use of ceramic membranes in the waste water treatment is limited by the cost of membranes which is often 5 to 10 times higher than that of organic membranes. Consequently, a great deal of research has been devoted in recent years to the developement of new types of inorganic membranes witch include zeolites [7], carbon [8] dense metals [9] and porous ceramic oxides [10]. The preparation of ceramic membranes from raw materials like clay and apatite is a novel approach witch has received only limited attention in the literature [4-11]. These materials are generally abundant (located throughout the world) and of a very low cost.

Thus, the development of clay-based inorganic membranes could lead to an important new technological application that would add economic value to the used of the membrane processes in the environment.

Membrane processes such as reverse osmosis (RO), nanofiltration (NF), ultrafiltration (UF), microfiltration (MF), dialysis, electrodialysis (ED), membrane electrolysis (ME) and diffusion dialysis (DD) are considered as first generation processes; whereas, second generation processes are gas separation (GS), vapour permeation (VP), pervaporation (PV), membrane distillation (MD), membrane contactors (MC) and carrier mediated processes. The performance or efficiency of a given membrane is determined by two parameters, its selectivity (for some processes measured as percent rejection or retention) and the flow (often denoted as flux or permeate rate) [12]. Microfiltration (MF) is a pressure-driven membrane process for the separation of fine particles, microorganisms and emulsion droplets. The membranes used have a microporous structure which separates fine particles with a size in the range of $0.02-20 \mu \mathrm{m}$. Therefore, MF is placed between ultrafiltration and coarse filtration, which is not a membrane operation. MF is the oldest membrane technology. It started at the beginning of this century with the preparation of synthetic microporous membranes based on cellulose [13]. Ultrafiltration is currently used for the concentration of a wide range of protein products, including recombinant therapeutics, industrial enzymes, and a variety of food and beverage products $[14,15]$. Ultrafiltration membranes are normally rated by their nominal molecular weight cut-off, which is typically defined as the molecular weight of a solute that has a rejection coefficient of $90 \%$. However, there is no standardization in this $90 \%$ value, and different manufacturers measure the rejection using solutes with very different physical properties and under very different operating conditions [16].

The aim of the present work was to compare filtration performance of two types of tubular ceramic membranes: commercial one based on alumina and elaborated Tunisian clay membranes. Experiments were carried out in order to reduce pollution load of the cuttlefish effluent generated from a sea product-freezing factory located in Sfax (Tunisia) which consumes a great amount of water for the washing baths (about $150-200 \mathrm{~m}^{3}$ /day) which is generally discharged in the littoral. Before freezing, the cuttlefish must be washed to eliminate black colour caused by the ink (containing melanin) contained in the animal bag, resulting in highly coloured wastewater [17].

*Corresponding author: Sabeur Khemakhem, Laboratoire des Sciences de Matériaux et Environnement, Faculté des Sciences de Sfax, Route de Soukra Km 4, 3038, Sfax, Tunisie, Tel: +216 97894904 ; Fax: +216 74 274437; E-mail: Khemakhem_sabeur@yahoo.fr

Received April 29, 2011; Accepted May 18, 2011; Published June 14, 2011

Citation: Khemakhem S, Amar RB (2011) Treatment of Industrial Effluents by MF and UF Ceramic Membranes: Comparative Study using Commercial and Elaborated Tunisian Clay Membranes. J Membra Sci Technol 1:105. doi:10.4172/2155-9589.1000105

Copyright: (c) 2011 Khemakhem S, et al. This is an open-access article distributed under the terms of the Creative Commons Attribution License, which permits unrestricted use, distribution, and reproduction in any medium, provided the original author and source are credited. 


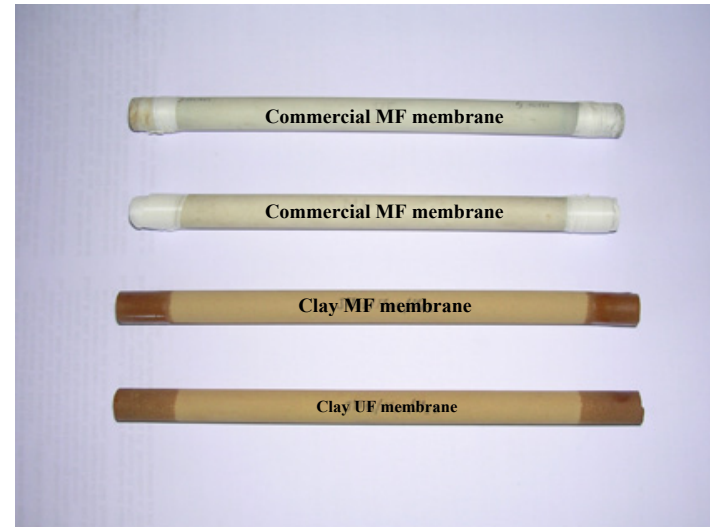

Figure 1: A photograph of variety of used MF and UF membranes.

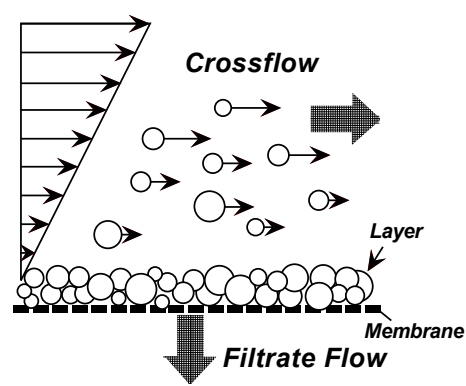

Figure 2: Principle of crossflow filtration.

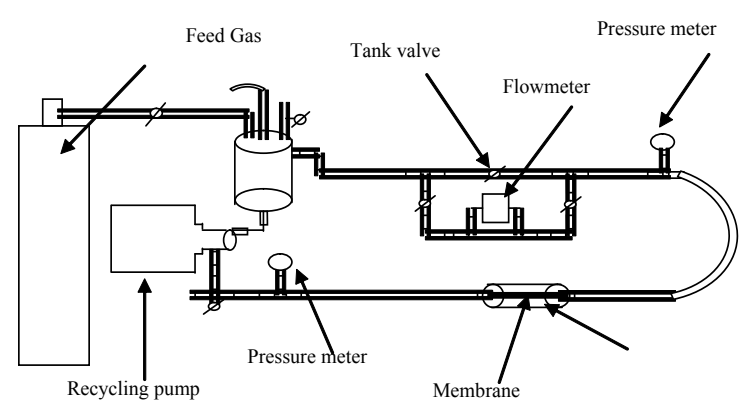

Figure 3: Pilot plant general scheme (microfiltration and ultrafiltration)

\section{Experimental}

\section{Materials}

Two types of the commercial tubular membranes supported on the alumina were purchased from Pall EXEKIA (Figure 1). Tubular membranes with external/internal diameter of $10 / 7 \mathrm{~mm}$ and the length of $150 \mathrm{~mm}$ were used. The structure of alumina support is macroporous (average pore diameter equal $0.8 \mu \mathrm{m}$ ). The microfiltration zirconia membrane has an average pore diameter of $200 \mathrm{~nm}$. The selective layer of the ultrafiltration membrane was prepared from titania with an average pore diameter of $5 \mathrm{~nm}$.

Two Tunisian clay membranes were prepared in our laboratory from the support to the finest layer. Tubular supports were elaborated with external/internal diameter of $9 / 7 \mathrm{~mm}$ and the length of $150 \mathrm{~mm}$ with an average pore diameters of $9.2 \mu \mathrm{m}$. Microfiltration layer present an average pore size of $0.18 \mu \mathrm{m}$ and ultrafiltration membrane with $15 \mathrm{~nm}$ diameter of pore.

\section{Apparatus}

Figure 2 shows the schematic diagram of the MF and UF pilot plant used for the treatment of the industrial effluent. The plant is equipped with a 5 litres feed tank. The transmembrane pressure was controlled by adjustable valves. It varies in the range of $0-3$ bars. The temperature is controlled by a cooling device inserted into the feed tank. In our case, the flow velocity and the temperature of the solution are fixed respectively at $2.5 \mathrm{~ms}^{-1}$ and $25^{\circ} \mathrm{C}$. The tubular membrane $(15$ $\mathrm{cm}$ length, $6 \mathrm{~mm}$ of diameter and $26 \mathrm{~cm}^{2}$ filtering area) takes place in a stainless steel carter. The transmembrane pressure was regulated by means of nitrogen gas. The membrane was conditioned by immersion in pure deionized water for a minimum of $24 \mathrm{~h}$ before filtration tests. The duration of each test normally varied from 1 to 3 hours. Permeate samples were taken and analysed at each run. A thermal treatment was used for membrane regeneration.

The techniques used to analyse collected samples of feed, retentate and permeate are reported below:

- Turbidity: using a HACH «2100 N Turbidimeter» turbidimeter.

- Dissolved organic carbon: using a «REHROTEST TRS 200 NFT 90101» COD analyser.

- Conductivity: using a «Consort K 911» conductimeter.

\section{Wastewater}

Wastewater samples were taken from the wastewaters produced by a sea-products freezing factory located in Sfax, Tunisia. In order to determine the physico-chemical characteristics of the effluent to be treated, the wastewater was monitored through daily sampling and analysis. A large number of analyses were conducted on each sample and the following parameters were measured: turbidity, COD, temperature, $\mathrm{pH}$ and conductivity. The COD values of raw effluent from the production process ranged between 6000 and $7000 \mathrm{mgL}^{-1}$ with an average concentration of $6042 \mathrm{mgL}^{-1}$. The turbidity measured for the raw effluent presents a very high value which is in order to 700 NTU (Table 1).

\section{Preliminary treatement of raw effluent}

The general scheme wastewater treatment generally involves two main stages: (i) a primary clarification (or primary treatment) using physico-chemical methods such as a coagulation/flocculation process with a flotation or decantation step to remove mainly the suspended solids and colloids, and (ii) a decontamination step (or

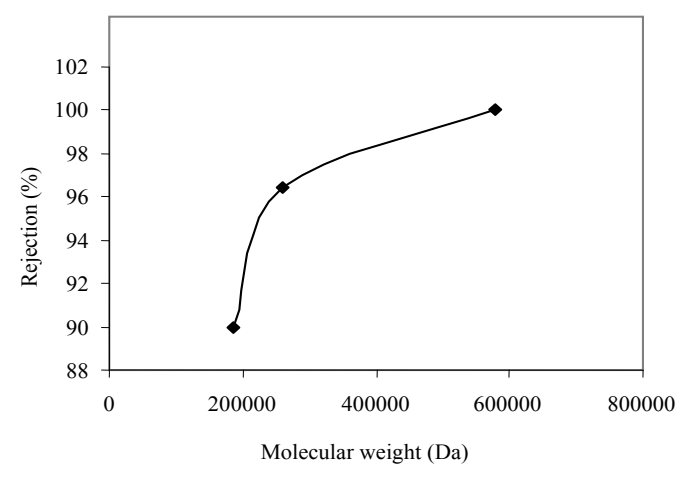

Figure 4: Rejection rates of dextran polymers. 


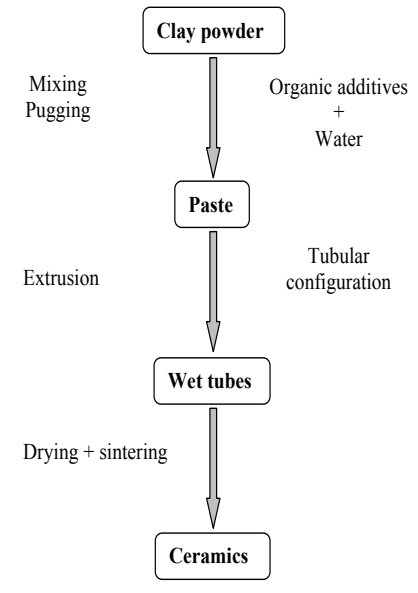

Figure 5: Various steps of preparation of porous ceramics.

\begin{tabular}{|l|l|l|l|l|}
\hline & Turbidity (NTU) & $\mathbf{C O D}\left(\mathbf{m g}_{\mathbf{L}}^{\mathbf{- 1}}\right)$ & Conductuvity $\left(\mathbf{m S} . \mathbf{c m}^{-1}\right)$ & $\mathbf{p H}$ \\
\hline Raw effluent & 700 & 6042.40 & 52 & 6.89 \\
\hline $\begin{array}{l}\text { Effluent after } \\
\text { coagulation }\end{array}$ & 49 & 3765.42 & 49.5 & 6.59 \\
\hline
\end{tabular}

Table 1: Turbidity, COD, conductuvity and $\mathrm{pH}$ of raw and coagulated effluent.

\begin{tabular}{|c|c|c|c|c|c|}
\hline & Pressure (bar) & $\begin{array}{l}\text { Turbidity } \\
\text { (NTU) }\end{array}$ & $\begin{array}{l}C O D \\
\left(m g \cdot L^{-1}\right)\end{array}$ & $\begin{array}{l}\text { Conductuvity } \\
\left(\mathrm{mS} . \mathrm{cm}^{-1}\right)\end{array}$ & $p H$ \\
\hline \multirow{3}{*}{$\begin{array}{l}\text { MF } \\
\text { Commercial } \\
\text { Membrane }\end{array}$} & 1 & 0.91 & 1467.44 & 50.54 & 6.03 \\
\hline & 2 & 1.39 & 1899.04 & 48.86 & 6.62 \\
\hline & 3 & 3.62 & 1985.36 & 45.66 & 6.32 \\
\hline \multirow{3}{*}{$\begin{array}{l}\text { MF Clay } \\
\text { Membrane }\end{array}$} & 1 & 0.86 & 1194.80 & 49.54 & 6.56 \\
\hline & 2 & 1.10 & 1381.12 & 54.40 & 6.47 \\
\hline & 3 & 1.57 & 1467.44 & 47.95 & 6.57 \\
\hline
\end{tabular}

Table 2: Turbidity, COD, conductuvity and $\mathrm{pH}$ of microfiltrated effluent by commercial and clay membrane.

\begin{tabular}{|c|c|c|c|c|c|}
\hline & $\begin{array}{l}\text { Pressure } \\
\text { (bar) }\end{array}$ & $\begin{array}{l}\text { Turbidity } \\
\text { (NTU) }\end{array}$ & $\begin{array}{l}\text { COD } \\
\left(m g \cdot L^{-1}\right)\end{array}$ & $\begin{array}{l}\text { Conductuvity } \\
\left(\mathrm{mS} . \mathrm{cm}^{-1}\right)\end{array}$ & $p H$ \\
\hline \multirow{3}{*}{$\begin{array}{l}\text { UF Commercial } \\
\text { Membrane }\end{array}$} & 1 & 0.85 & 1367.44 & 45.50 & 5.74 \\
\hline & 2 & 1.15 & 1565.50 & 37.50 & 5.97 \\
\hline & 3 & 2.06 & 1830.60 & 47.90 & 5.94 \\
\hline \multirow{3}{*}{$\begin{array}{l}\text { UF Clay } \\
\text { Membrane }\end{array}$} & 1 & 0.70 & 1095.45 & 35.50 & 5.81 \\
\hline & 2 & 1.05 & 1225.50 & 48.90 & 5.94 \\
\hline & 3 & 1.80 & 1405.50 & 46.70 & 6.03 \\
\hline
\end{tabular}

Table 3: Turbidity, COD, conductuvity and $\mathrm{pH}$ of ultrafiltrated effluent by commercial and clay membrane.

\begin{tabular}{|c|c|c|c|c|c|}
\hline & $\begin{array}{l}\text { Pressure } \\
\text { (bar) }\end{array}$ & $\begin{array}{l}\text { Turbidity } \\
\text { (NTU) }\end{array}$ & $\begin{array}{l}C O D \\
\left(m g \cdot L^{-1}\right)\end{array}$ & $\begin{array}{l}\text { Conductuvity } \\
\left(\mathrm{mS} . \mathrm{cm}^{-1}\right)\end{array}$ & $p H$ \\
\hline \multirow{3}{*}{$\begin{array}{l}\text { MF+UF Commercial } \\
\text { Membrane }\end{array}$} & 1 & 0.80 & 1120 & 43.40 & 5.64 \\
\hline & 2 & 1.05 & 1270 & 41.30 & 5.36 \\
\hline & 3 & 1.76 & 1435 & 43.80 & 5.44 \\
\hline \multirow{3}{*}{$\begin{array}{l}\text { MF+UF Clay } \\
\text { Membrane }\end{array}$} & 1 & 0.64 & 867 & 43.50 & 5.86 \\
\hline & 2 & 0.95 & 1027 & 44.60 & 5.27 \\
\hline & 3 & 1.46 & 1143 & 45.20 & 5.43 \\
\hline
\end{tabular}

Table 4: Turbidity, COD, conductuvity and $\mathrm{pH}$ of permeat obtained by microfiltration associated with ultrafiltration.

secondary treatment) using membrane treatement. Flocculation using flocculating agents is widely used in industrial processes including water and wastewater treatment $[18,19]$. The coagulation/flocculation process consists of combining insoluble particles (suspended solids, colloids) and/or dissolved organic matter into large aggregates, thereby facilitating their removal in subsequent sedimentation, floatation and filtration stages. The flocculating agents used can be classified into three groups [18-20]: (i) mineral additives including metal salts such as polyaluminium chloride (PAC), (ii) synthetic organic polymer such as polyacrylamide- and polyacrylate-based materials and (iii) naturally occurring flocculants such as sodium alginate and starches.

In this stady before the filtration runs, a pre-treatment process consisting in coagulation using Alumina salt was performed in order to prevent the fouling on the membrane surface by reducing the pollution load. Based on experimental studies of Ellouze et al. [21], the coagulation process is largely enhanced by the addition of aluminium salt (optimal quantity is $165 \mathrm{mg} / 1$ ) to the effluent pretreated with, due to the increase of density of flocs (large particles) formed by the association of fine colloids which can be removed by prefiltration.

\section{Microfiltration}

Microfiltration experiments were carried out on the pilot units (Figure 2), functioning in mono-staged mode of tangential filtration. The transmembrane pressure (TMP) was controlled by an adjustable valve at the filter outlet. It varies in the range of 1-3 bar. Temperature was kept at $25^{\circ} \mathrm{C}$ by a thermal exchange system. In crossflow microfiltration CMF, the fluid to be filtered flows parallel to the membrane surface and permeates through the membrane due to a pressure difference (Figure 3 ). The permeability of interest in microfiltration or ultrafiltration process is that with respect to the solvent Eq. (1):

$$
L_{P}=\frac{J_{V}}{\Delta P}
$$

Where $J \mathrm{v}$ is the volumetric filtrate flux (volume flow rate per membrane area) and $\Delta P$ is the transmembrane pressure driving force. $L p$ is often referred to as the hydraulic permeability since water is the typical solvent, and the data are often normalized by the solvent viscosity to account for the effects of temperature.

Microfiltraion permeat was always collected to measure the initial turbidity, COD, $\mathrm{pH}$ and conductivity. Before and after each experiment, membranes were cleaned by basic acid washing and the system was rinsed with distilled water before and after each washing. Permeability of membranes by distilled water was measured until the initial permeability was achieved.

\section{Ultrafiltration}

Ultrafiltration experiments were carried out on the same pilot units (Figure 2) and with same conditions used in microfiltration prosses. Ultrafiltration membranes are normally rated by their nominal molecular weight cut- off, which is typically defined as the molecular weight of a solute that has a rejection coefficient of $90 \%$. Concentration was determined by ionic chromatography and the rejection rates, denoted $R$, were calculated using Eq. (2).

$$
R=\left(1-\frac{C}{C_{0}}\right) \times 100
$$

Where $C 0$ represents the initial concentration of the salted solution and $C$, the concentration of permeate. For clay ultrafiltraion membrane a rejection rate of $90 \%$ is obtained for molecular weight larger than $185 \mathrm{kDa}$, this value will be considered as the cutoff of the synthesized membrane (Figure 4).

\section{Microfiltration associated with Ultrafiltration}

The first step carried out in this part is a microfiltration. Permeate obtained by microfiltration is collected in a large beaker. It is poured 


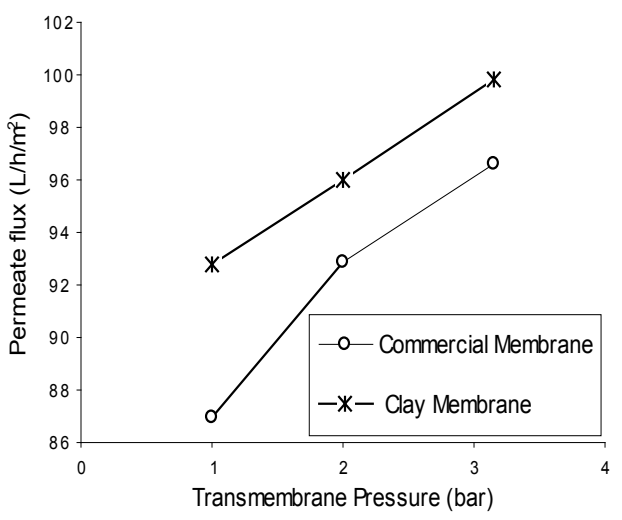

Figure 6: Variation of permeate flux with TMP for microfiltration membranes.

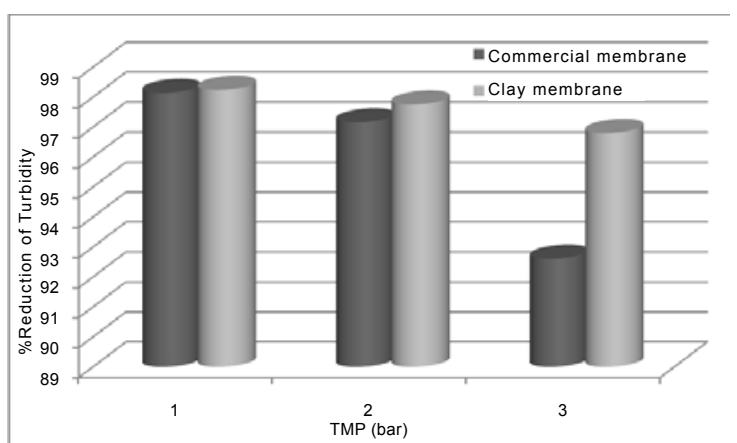

Figure 7: Effect of transmembrane pressures in microfiltration on turbidity reduction.

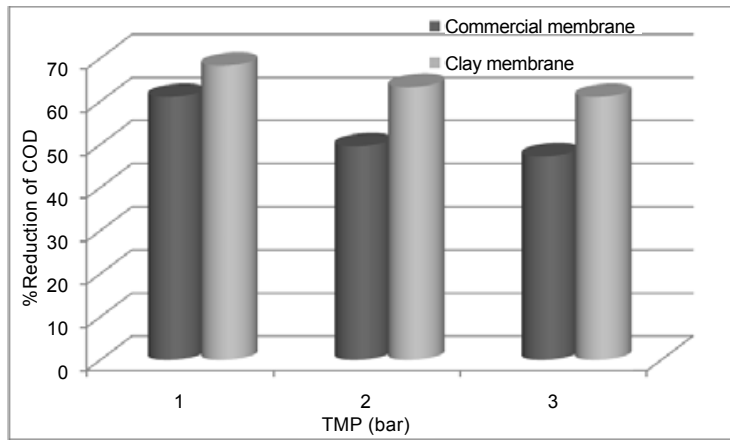

Figure 8: Effect of transmembrane pressures in microfilration on COD reduction.

into the tank of the filtration pilot. The microfiltration membrane is changed by an ultrafiltration membrane. It is then processed again by the ultrafiltration membrane. The same filtration conditions are followed for this type of procedure. In order to determine the physicochemical characteristics of the obtained permeate after the tow step microfiltration and ultrafiltration permeate was analyzed. A large number of analyses were conducted on each sample and the following parameters were measured: turbidity, COD, conductivity and $\mathrm{pH}$.

\section{Preparation and characterisation of the membrane}

Clay powders mixed with some organic additives can be extruded to form a porous tubular support. After firing, the support showed an average pore diameter of $9 \mu \mathrm{m}$ and a porosity of $49 \%$. This porous ceramic tube was used as support to prepare microfiltration and ultrafiltration membranes [22].

The elaboration of macroporous ceramics was carried out by shaping of a ceramic paste, followed by the consolidation by sintering. The process of development is described in (Figure 5). The preparation of the active layer based on clay too was performed by the slip casting method. A deflocculated slip was obtained by mixing a mineral powder, PVA (12 wt \%), and water. The water permeability measured for the membranes calcinated at $900^{\circ} \mathrm{C}$ and with a mean pore size of $0.18 \mu \mathrm{m} 8671 . \mathrm{h}^{-1} \cdot \mathrm{m}^{-2} \cdot \mathrm{bar}^{-1}$. The obtained membranes can be used in microfiltration process [10]. Illite ultrafiltration top layer with $15 \mathrm{~nm}$ average pore size, have been deposit on the clay microfiltration layer previously prepared using aqueous colloidal suspensions. The top layer thickness was about $5 \mu \mathrm{m}$ [11].

\section{Results and Discussion}

\section{Coagulation performances}

Table 1 shows a comparison between raw and pre-treated effluent by coagulation process. Alumina salt is coagulan agents used on COD and turbidity reduction performance. The COD values of raw effluent is $6042.40 \mathrm{mg} \cdot \mathrm{L}^{-1}$. After coagulation process, the COD values obtined is $3765.42 \mathrm{mg} . \mathrm{L}^{-1}$. The turbidity values of raw effluent decreased from $700 \mathrm{NTU}$ to $49 \mathrm{NTU}$ after coagulation process. The results showed that coagulation process lowered COD by $38 \%$ and turbidity by $93 \%$. Table 1 shows that the treated effluent can be potentially highly polluted even after treatment by coagulation, the degree of pollution well explained by the high values of COD and turbidity.

\section{Microfiltration performances}

MF test carried out by keeping constant the initial concentration of the raw effluent by returning both permeate and concentration to the feed reservoir. This run was carried out to obtain preliminary information about the fouling tendency of the membrane through the study of the behaviour of the permeate flux as a function of operating time as well as of the transmembrane pressure (TMP).

Figure 6 shows the variation of permeate flux versus the TMP for microfiltration membranes. This Figure shows that the permeate flux is linearly increased with increasing TMP for clay and commercial membrane. However, the performances in term of permeate flux are slightly better with the clay membranes. The MF permeate flux is about $93 \mathrm{l} / \mathrm{h} \cdot \mathrm{m}^{2}$ for clay membranes and $87 \mathrm{l} / \mathrm{h} \cdot \mathrm{m}^{2}$ for UF membrane. The obtained results refer to average samples taken at different periods of experiments. Table 2 shows that the quality of permeate seems to be highly satisfactory in term of turbidity and COD reduction for commercial and clay membrane. The conductivity values were usually in the range of $45-50 \mathrm{mS} . \mathrm{cm}^{-1}$. The turbidity of the microfiltrated effluent by commercial membrane was $0.91,1.39$ and 3.62 NTU respectively for 1,2 and 3 bar. For permeat obtained by clay membrane the values of turbidity was $0.86,1.1$ and 1.57 respectively for 1,2 and 3 bar. Turbidity values of permeat obtained by caly membrane were significantly lower then obtained by commercial membrane. The COD values were in the range of $1467-1985 \mathrm{mg} . \mathrm{L}^{-1}$ for commercial membrane and in the range of $1194-1467 \mathrm{mg} . \mathrm{L}^{-1}$ for clay membrane. The effect of transmembrane pressures on turbidity and COD rejection was depicted in Figure 7 and Figure 8 . The retention of Turbidity was about $98.14 \%$ for commercial membrane and $98.24 \%$ for clay membrane when operated at 1 bar TMP. At lower pressures high retention was found for tow type of membrane. As pressure increases, more melanin permeates through the membrane leaving most of solutes to through the pores of the 


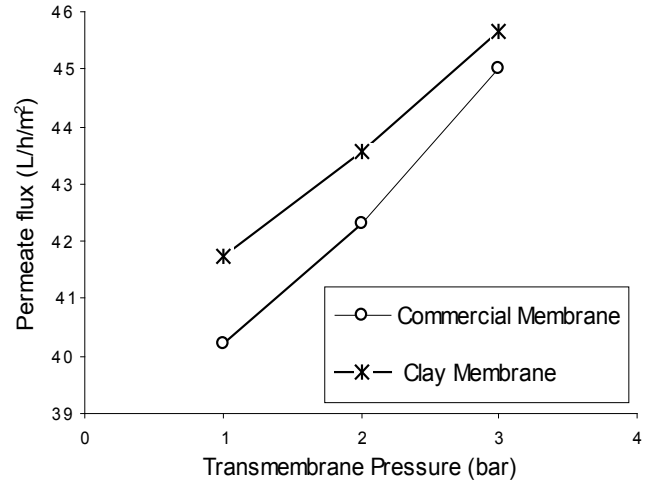

Figure 9: Variation of permeate flux with TMP for ultrafiltration membranes.

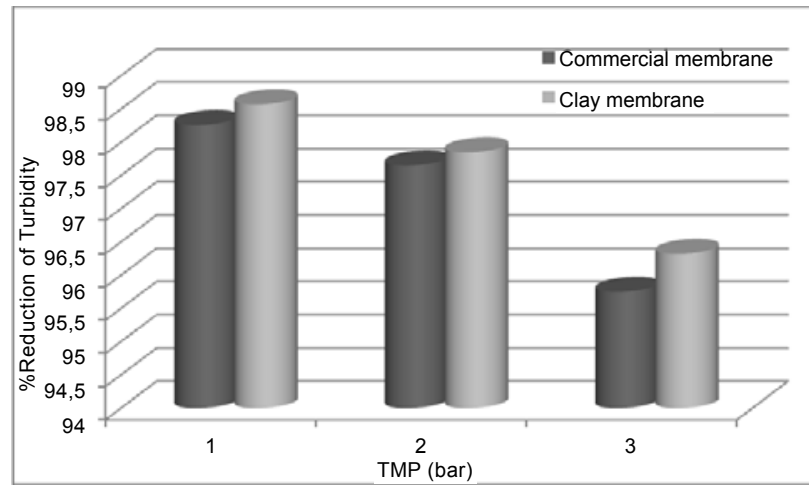

Figure 10: Effect of transmembrane pressures in ultrafiltration on turbidity reduction.

membrane by increasing transmembrane pressure and subsequently decreased rejection.

\section{Ultrafiltration performances}

In a general way, effluents showed a remarkable fouling character with respect to ultrafiltration membranes, as shown by comparisons with flux water. The nature of the permeat had a strong impact on ultrafiltration performances.

Figure 9 shows the evolution of permeate flux versus transmembrane pressure for each one of commercial ultrafiltration membrane and elaborated ultrafiltration clay membrane. For two types of used membranes the flux of permeate increased with transmembrane pressure applied. Flux of permeate obtained for clay membrane is higher than those recorded with commercial membrane. Indeed, permeate flux is $42 \mathrm{l} / \mathrm{h} \cdot \mathrm{m}^{2}$ for clay membrane and $40 \mathrm{l} / \mathrm{h} \cdot \mathrm{m}^{2}$ for commercial membrane.

Table 3 gives the main physicochemical parameters analyzed for permeate obtained by UF commercial membrane and UF clay membrane. These analyses show variability in the turbidity and COD values for two types of membranes. This variability depends essentially on the nature and performance of the used membranes.

For commercial membrane, the values of COD (from 1367 to $1830 \mathrm{mg} \mathrm{L}^{-1}$ with TMP from 1 to 3 bar) and of turbidity (from 0,85 to $2.06 \mathrm{mg} \mathrm{L}-1$ with TMP from 1 to 3 bar). For clay membrane, the values of COD (from 1095 to $1405 \mathrm{mg} \mathrm{L}^{-1}$ with TMP from 1 to 3 bar) and of turbidity (from 0,7 to $1.8 \mathrm{mg} \mathrm{L}-1$ with TMP from 1 to 3 bar). Percentage reduction of turbidity and COD as a function of TMP has been shown in Figure 10 and Figure 11. Both the trbidity and COD reduction have been found to increase with decrease in TMP, which could be attributed due to the higher rejection at lower TMP. Turbidity of permeate was found to get reduced by $98.26 \%$ for commercial membrane and $98.57 \%$ for clay membrane when UF was carried out at a TMP of 1 bar, whereas, COD was reduced by only $63.67 \%$ for commercial membrane and $70.9 \%$ for clay membrane a TMP of 1bar. In fact, at all the TMP level, turbidity reductions were found to be more than the corresponding COD reduction on percentage basis. As the COD is caused by the presence of low molecular inorganic chemicals also, which might pass through the membrane, may give less \%-COD. In term of quality, Figure 12 shows a noticeable elimination of suspended matter illustrated by the change of the effluent colour as well as the elimination of the turbidity.

\section{Ultrafiltration performances combined with microfiltration}

Table 4 shows average reduction of COD and turbidity retention compared to other process. In order to explain these differences, a physico-chemical analysis of permeate has shown important composition disparities between effluents resulting from this processes and the two other process used previously. Like other processes, percentage of reduction of COD and turbidity increased at height transmembrane process. The combination of ultrafiltration with microfiltration shows a very height performances to those obtained with microfiltration or ultrafiltrtion alone. The compatibility of this process proved to be excellent.

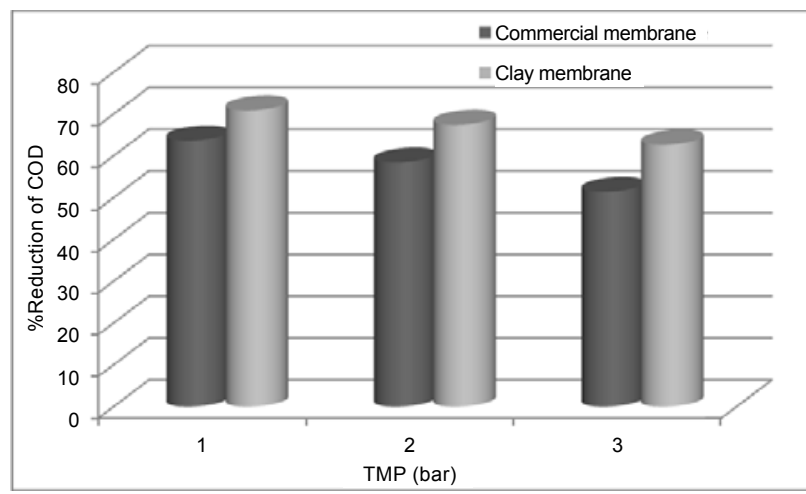

Figure 11: Effect of transmembrane pressures in ultrafiltration on COD reduction.

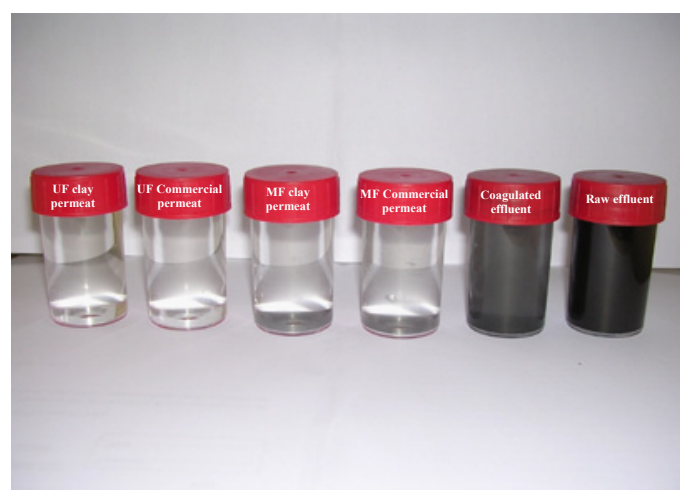

Figure 12: A photograph of cuttlefish effluent before and after MF and UF treatment. 
Citation: Khemakhem S, Amar RB (2011) Treatment of Industrial Effluents by MF and UF Ceramic Membranes: Comparative Study using Commercial and Elaborated Tunisian Clay Membranes. J Membra Sci Technol 1:105. doi:10.4172/2155-9589.1000105

\section{Membrane regeneration}

After each experiment, the membrane must be regenerated. The efficiency of the using protocol is verified by the measurement of water flux. The regeneration of the membrane was carried out by firstly, thermal treatment at $300^{\circ} \mathrm{C}$ during $1 \mathrm{~h}$, and secondly, by leaving the membrane in distilled water. The used protocol appears sufficient because we obtained the value of the initial permeability of the membranes.

\section{Conclusion}

The purpose of this study was to evaluate the performance of the clay membranes developed in our laboratory, in the cuttlefish effluent treatment. A comparison with commercial membranes put into evidence the great importance from an economic point of view of membranes based on local material in the waste water treatment. Good performances were observed in term of permeate flux and pollution retention. For MF clay membrane, permeate flux reached $100 \mathrm{l} / \mathrm{h} \cdot \mathrm{m}^{2}$ at a transmembrane pressure of 3 bars. This value corresponds to the range of permeate flux values usually recommended at an industrial scale.

\section{References}

1. Suksaroj C, Héran M, Allègre $C$, Persin F (2005) Treatment of textile plan effluent by nanofiltration and/or reverse osmosis for water reuse. Desalination, 178: 333-41.

2. Burggraaf AJ, Cot L (1996) Fundamentals of Inorganic Membranes Science and Technology.Membrane Science and Technology. Series 4, Elsevier, New York, 21.

3. Gonzalez MP, Navarro R, Saucedo I, Avila M, Revilla J, et al. (2002) Purification of phosphoric acid solutions by reverse osmosis and nanofiltration. Desalination, 147: 315-320.

4. Khemakhem S, Ben Amar R, Ben Hassen R, Larbot A, Cot L, et al. (2006) Fabrication of mineral supports of membranes for microfiltration / ultrafiltration from Tunisian clay. Ann Chim Sci Mat 31:169-181.

5. T. Matsuura, (1994) Synthetic Membranes and Membrane Separation Processes CRC Press, Ann Arbor, MI.

6. Ben Amar N, Kechaou N, Ben Amar R, Palmeri J, Deratani A, (Mai 2007) Traitements membranaires d'effluents de l'industrie textile et dimensionnement d'une unité nanofiltration - Cas de la SITEX. , TIWATMED , Djerba.
7. Lovallo MC, Tsapatsis M, (1996) Perferentially oriented submicron silicite membranes. AlChE, 42: 3020-3029.

8. Katsarosa FK, Steriotisa TA, Stubosb AK, Mitropoulosa A, Kanellopoulosa NK et al.(1997) High pressure gas permeability of microporous carbon membranes. Microporous Matls, 8:171-176.

9. Zaman J, Chakma A, (1994) Inorganic membrane reactors. J. Membr. Sci, 92 1-28.

10. Gillot J, Garcera D, (Octobre 1984) New ceramic filter media for crossflow microfiltration and ultrafiltration, Filtra, SFF Paris, 84: 2- 4.

11. Khemakhem S, Ben Amar R, Larbot A, (2007) Synthesis and characterization of a new inorganic ultrafiltration membrane composed entirely of Tunisian natural illite clay. Desalination 206: 210-214.

12. Roy S, Chowdhury, Kumar P, Bhattacharya PK, Kumar A, (2001) Separation characteristics of modified polysulfone ultrafiltration membranes using NOx, Separation and Purification Technology, 24:271-282.

13. Ripperger S, Altmann J (2002) Crossflow microfiltration-state of the art Separation and Purification Technology. 26: 19-31.

14. van Reis R, Zydney AL, (1999) Protein ultrafiltration, in: M.C. Flickinger, S.W Drew (Eds.), Fermentation, Biocatalysis, and Bioseparation: Encyclopedia of Bioprocess Technology, John Wiley \& Sons Inc, pp. 2197-2214.

15. Wang WK, (2001) Membrane Separations in Biotechnology. second ed. Marcel Dekker Inc.

16. Amit Mehta andAndrew L. Zydney, (2005) Permeability and selectivity analysis for ultrafiltration membranes. Journal of Membrane Science, 249:245-249.

17. Abdelmouleh A, (1997) Etude expérimentale de la valorisation de l'allache et de la seiche en Tunisie, Thèse de doctorat, Sfax.

18. Bratby J (2007) Coagulation and Flocculation in Water and Wastewater Treatment, 2nd ed., IWA Publishing.

19. Stechemesser H, Dobia`s, B (2005) Coagulation and flocculation. Surfactant Sciences Series, vol. 126, 2nd ed., CRC Press.

20. Bolto, Brian A (1995) Soluble polymers in water purification, Prog. Polym. Sci, 20: $987-1041$.

21. Ellouze E, Ben Amar R, Bouffi S, Ben Salah AH (2003) J. Environ. Technol. 24 1357-1366

22. Khemakhem S, Larbot A, Ben Amar R (2009) New ceramic microfiltration membranes from Tunisian natural materials. Application for the cuttlefish effluents treatment, Ceramics International, 35: 55-61. 